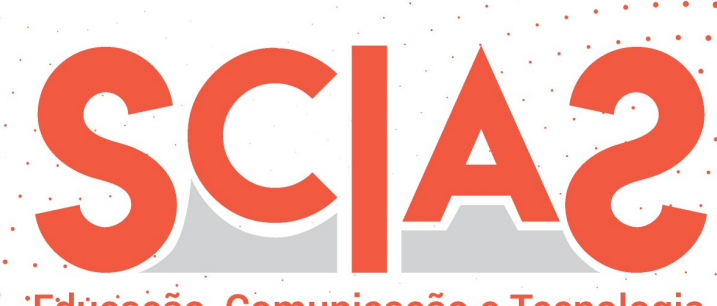

'Edúçaçã̃o, Comunicação e Tecnologia'

Atribuição BB CY 4.0

\title{
O analógico e o digital na obra de Sebastião Salgado: Dispositivos e processos de edição
}

\author{
Eliziane Cristina da Silva de Oliveira ${ }^{1}$ \\ Wagner José Moreira ${ }^{2}$
}

\section{Resumo}

A partir das reflexões sobre o dispositivo propostas por Michael Foucault e compiladas por Gilles Deleuze, a proposta deste trabalho é iniciar uma investigação sobre os processos de edição fotográfica utilizados por Sebastião Salgado em dois momentos tecnológicos distintos de sua carreira: o uso de câmeras fotográficas digitais e analógicas, bem como a transição entre as duas tecnologias e a adaptação e criação de técnicas e fluxos de trabalho. Nesse primeiro movimento de investigação, foram analisadas as falas de Sebastião Salgado no livro autobiográfico De minha terra à Terra, lançado no Brasil em 2014, e no documentário Revelando Sebastião Salgado, de 2013. Foi possível apontar, preliminarmente, que a migração tecnológica vem causando impactos significativos na metodologia de construção de discursos fotográficos pelo fotógrafo.

\section{Palavras-chave}

Sebastião Salgado. Fotografia analógica. Fotografia digital. Dispositivos. Processos de edição.

Recebido em: 16/06/2020

Aprovado em: 25/06/2020

\footnotetext{
${ }^{1}$ Doutoranda e Mestre em Estudos de Linguagem pelo Centro Federal de Educação Tecnológica de Minas Gerais (CEFET-MG). Jornalista, fotógrafa e professora.

Email: elizianes@hotmail.com

${ }^{2}$ Doutor em Literaturas de Língua Portuguesa pela Pontifícia Universidade Católica de Minas Gerais. Professor do Centro Federal de Educação Tecnológica de Minas Gerais (CEFET-MG).

Email:wgnrjs@gmail.com
} 


\section{Analog and digital in the work of Sebastião Salgado: Devices and editing processes}

\section{Abstract}

From the reflections on the device proposed by Michael Foucault and compiled by Gilles Deleuze, the purpose of this work is to initiate an investigation on the photo editing processes used by Sebastião Salgado in two distinct technological moments of his career: the use of digital cameras and analog, as well as the transition between the two technologies and the adaptation and creation of techniques and workflows. In this first investigation movement, the speeches of Sebastião Salgado were analyzed in the autobiographical book De minha terra à Terra, released in Brazil in 2014, and in the documentary Revelando Sebastião Salgado, from 2013. It was possible to point out, preliminarily, that technological migration has been causing significant impacts on the methodology of construction of photographic discourses by the photographer.

\section{Keywords}

Sebastião Salgado. Analog photography. Digital photography. Devices. Editing processes. 


\section{Introdução}

A partir das reflexões sobre o dispositivo propostas por Michael Foucault e compiladas por Gilles Deleuze, a proposta deste trabalho é iniciar uma investigação sobre os processos de edição fotográfica utilizados por Sebastião Salgado em dois momentos tecnológicos distintos de sua carreira: o uso de câmeras fotográficas digitais e analógicas, bem como a transição entre as duas tecnologias e a adaptação e criação de técnicas e fluxos de trabalho. Nesse primeiro movimento de investigação, foram analisadas as falas de Sebastião Salgado no livro autobiográfico De minha terra à Terra, lançado no Brasil em 2014, e no documentário Revelando Sebastião Salgado, de 2013.

Ao observar as falas de Salgado, especificamente ao relatar como foi feita a transição entre as chamadas fotografia analógica e a digital e também como se dá seu processo de edição fotográfica, que se mantém parcialmente inalterado a despeito da mudança de tecnologia, como discutiremos à frente, surgem questionamentos e inquietações sobre a adoção de técnicas semelhantes de uma prática fotográfica que o próprio fotógrafo considera que tenha "mudado muito e mudado muito pouco” (Revelando Sebastião Salgado, 2012,1h5’32”)

Diante disso, poderíamos considerar câmeras fotográficas analógicas e digitais como um mesmo dispositivo de produção e/ou construção de imagens e narrativas? Ainda que o funcionamento das câmeras SLR (single-lens reflex) e das DSLR (digital single-lens reflex) seja semelhante no que diz respeito à parte óptica, a captação e gravação da imagem fotografada passa de uma película fotossensível, o filme, para um sensor elétrico que passa a captar pontos luminosos. Esses dois processos distintos podem dar origem a imagens ampliadas, e não mais reveladas, semelhantes, ou iguais para um observador não conhecedor destas diferenças tecnológicas e procedimentais. Mas, para o fotógrafo que conhece as técnicas e é capaz de diferenciar e, ao mesmo tempo, operar no universo das duas tecnologias, como se dá a aplicação das mesmas técnicas de edição nesses dois universos distintos? 
Se pranchas de contato são obtidas a partir das tiras de filmes revelados e copiados no papel fotossensível, sem ampliação, poderíamos chamar de folha de contato o material que é obtido a partir da transposição de arquivos digitais para negativos? Essas pranchas de contato analógicas e digitais seriam o mesmo dispositivo de leitura e edição?

É a partir dessas inquietações que iniciaremos nossas reflexões, mais com intenção e vontade de compreender esses processos fotográficos do que encontrar respostas definitivas para esses questionamentos.

\section{Os objetos de provocação}

Para este estudo, foram selecionados dois objetos nos quais é possível ler e ouvir o que o próprio Sebastião Salgado diz, publicamente, sobre sua transição da fotografia analógica para a fotografia digital e também sobre seu processo de edição: o documentário Revelando Sebastião Salgado, de Betse de Paula e Juliano Ribeiro Salgado, e o livro autobiográfico Da minha terra à Terra (2014).

Publicado no Brasil em 2014, Da Minha terra à Terra é a primeira biografia ou autobiografia - do fotógrafo Sebastião Salgado, brasileiro nascido na cidade de Aimorés, Minas Gerais, em 1944, mas radicado na França desde o final dos anos 1960, para onde emigrou para se proteger das perseguições políticas realizadas pela ditadura militar no Brasil (1964-1985). Embora a obra de Sebastião Salgado seja amplamente conhecida no Brasil e em todo o mundo, até o lançamento da biografia pouco se sabia ou se conhecia sobre o fotógrafo e como sua história tem influência direta nos trabalhos que realiza, tanto nos aspectos técnicos, estéticos e até mesmo éticos.O fotógrafo escreve ainda sobre a transição da fotografia analógica para a digital, bem como sobre os processos de edição de imagens.

Para este trabalho, especificamente, abordaremos o capítulo 21 da obra, em que Sebastião Salgado fala sobre a transição da fotografia analógica para a fotografia digital, num processo que ele mesmo chama de "minha revolução digital". Partindo dessa afirmativa do fotógrafo, tomaremos por revolução aquilo que se 
transforma, ainda que este posicionamento seja distinto daquilo que Sebastião Salgado tenha afirmado ao adotar o uso da tecnologia digital na execução de seus projetos fotográficos. Neste breve capítulo de apenas cinco páginas, Sebastião Salgado consegue expor os motivos que o levaram pelo caminho da fotografia digital e quais as preocupações que, até então, tinha em relação ao registro digital de sua fotografia: os problemas que enfrentava com filmes, sejam as dificuldades do médio formato utilizado no Projeto Gênesis ou a vistoria e conferência manual de grande quantidade de material nos aeroportos; a poluição ambiental causada pelo grande volume de produtos químicos reveladores e fixadores - despejado nas redes públicas de esgoto; e a insegurança quanto ao arquivamento dos arquivos digitais das fotografias. Essas questões, anteriormente sem respostas foram sanadas gradativamente. Neste trabalho, abordaremos prioritariamente a transposição dos arquivos digitais para negativos, o que impactaria mais fortemente nas reflexões sobre os processos de edição fotográfica. Outro aspecto que consideramos importante na escolha da tecnologia digital por Sebastião Salgado diz respeito à preservação ambiental, uma vez que o processo de impressão de arquivos digitais elimina o despejo de produtos químicos como reveladores e fixadores nas redes de coleta de esgoto das cidades e, consequentemente, diminui o risco de contaminação das águas e do solo.

O documentário Revelando Sebastião Salgado, dirigido por Betse de Paula e Juliano Ribeiro Salgado, foi lançado no Brasil em 2013 e teve passagens por importantes festivais de cinema brasileiros, como o Festival de Gramado e o Festival de Brasília. Em formato de entrevista intimista, o documentário mostra, além da história de vida, a trajetória profissional de Sebastião Salgado. Essas duas vertentes se fundem ao longo do filme para mostrar o lado humano do fotógrafo. Assim como em sua autobiografia literária Da minha terra à Terra, em Revelando Sebastião Salgado, é o fotógrafo que fala para o cineasta e para a jornalista que o entrevista, apontando situações e momentos importantes ao longo de sua vida.

Observar as duas peças narrativas - filme e livro - nos possibilita perceber uma certa coerência nas ideias e falas de Sebastião Salgado nos aspectos que nos 
interessam nesse trabalho: a produção de fotografias, sejam analógicas ou digitais, e os processos de edição fotográfica, independente da nomenclatura que dermos aos dispositivos e instrumentos tecnológicos e técnicos disponíveis.

\section{Os dispositivos}

As reflexões realizadas nesse trabalho têm como partida os conceitos e as dimensões de dispositivo elaboradas e discutidas por Deleuze (1990) a partir de reflexões propostas por Michael Foucault. Embora essa abordagem considere dispositivos concretos como construções ou projetos arquitetônicos, nesse trabalho fizemos a opção por adotar como dispositivo não somente os aparatos técnicos e tecnológicos utilizados por Sebastião Salgado em suas produções fotográficas, mas optamos por uma tentativa e uma possibilidade de compreender os dispositivos como sistemas ou processos dinâmicos cujo funcionamento somente é possível pela interação entre homem e máquina, uma vez que, sozinho, o dispositivo não é capaz de produzir imagens ou narrativas. A partir dessa relação entre sujeito e objeto são feitas leituras subjetivas das situações do mundo e construídas narrativas que são dadas a ver. Se para Deleuze, compreender um dispositivo passa por desmembrá-lo em diversos aspectos físicos e relacionais, seguiremos por essa diretriz para refletir sobre o uso de câmeras fotográficas analógicas e digitais e sobre os processos de edição do material produzido por esses dispositivos.

Somados aos conceitos de dispositivo de Foucault e Deleuze, seguimos nossas reflexões juntamente Silva (2016), que, ao realizar pesquisas especificamente sobre a fotografia e suas implicações tecnológicas e técnicas, traz luzes sobre alguns conceitos que nos são úteis nesse momento.

Técnica e tecnologia, apesar de serem indissociáveis apresentam uma hierarquia existencial que deve ser notada: a técnica origina a tecnologia, ao mesmo tempo que não existe uma tecnologia que não esteja a serviço de uma técnica. (Silva, 2016, p. 27)

Silva (2016) adota como conceito que "tecnologia é a conjunção do material e da teoria que foram originados por uma técnica, sendo que esta corresponde à expressão prática da necessidade e desejo que levam a uma ação", sendo assim, no caso da fotografia, a tecnologia seria o conjunto existente e disponível de 
aparatos e o uso social que os envolve, enquanto a técnica seria o uso ou a operação que se faz desses dispositivos com uma finalidade discursiva ou em função de uma subjetividade do fotógrafo.Nesse caso, o domínio da técnica, embora aparentemente objetivo, estaria a serviço da subjetividade do fotógrafo.

No caso do trabalho de Sebastião Salgado, ressalta-se a existência e o uso de duas tecnologias (analógica e digital) e de uma técnica usada subjetivamente para a produção artística e discursiva. Em nossa análise, a fotografia está intimamente atrelada à tecnologia e ao desenvolvimento e aprimoramento de técnicas para o uso subjetivo e criativo da tecnologia. Pensamos, assim, a fotografia como meio de expressão, independente das tecnologias contemporâneas, ou atuais, para usar o mesmo conceito de Foucault.

Sendo assim, nossa proposta é assumir o conceito de fotografia como tecnologia porque Sebastião Salgado, ao que nos parece, embora use a tecnologia digital, tenta manter alguns procedimentos (técnicas) para produzir suas fotografias e narrativas, inclusive ao transpor os arquivos gerados digitalmente para "negativos", que seriam, então, marcas de uma fotografia analógica, marcada pela junção da física, ao obter imagens em dispositivos óticos, e da química, ao fixá-las em uma superfície física fotossensível, como o filme ou o papel fotográfico.

É por tal razão que a observação da tecnologia da fotografia parece ser um caminho para favorecer essa dualidade de abordagem, uma vez que lida com o universo da prática propriamente dita: a lógica funcional dos objetos e processos desse modo de se compor imagens, por ser a concretização das motivações que envolvem o saber e fazer fotográficos, permite investigar as bases teórico-filosóficas das relações entre o sujeito e a realidade visível. Além do que, pode-se apontar a tecnologia como ponto de ancoramento dos debates sobre a contemporaneidade da prática, pois é ali que o universo digital age numa possível redefinição de paradigmas para o uso da fotografia. (Silva, 2016, p. 24)

Embora as tecnologias sejam distintas e em constante mudança com o passar do tempo, independente da opção de suporte físico que se faça para fotografar e registrar as imagens, no caso de Sebastião Salgado, nos parece que a forma de olhar o mundo por meio do visor das câmeras ainda é a primeira edição feita pelo fotógrafo, ao escolher entre o que está visível o quadro que fotografa. 
Embora consideremos relevantes as influências bressonianas, bem como dos demais fotógrafos fundadores da Agência Magnum, onde Sebastião Salgado trabalhou durante 15 anos (1979-1994), percebemos, ao observar o novo fluxo de trabalho do fotógrafo, a existência de novas etapas no processo de edição das fotografias digitais que, em alguma medida, podem trazer, sim, mudanças significativas na construção das narrativas de Sebastião Salgado.

\section{Câmeras fotográficas analógicas e digitais}

O processo de captura de imagens e fixação desta no que chamamos de fotografia analógica se dá com a passagem da luz pelas lentes, pelo diafragma e pelo obturador e a gravação da imagem em uma película recoberta de emulsão química (Villegas, 2009). E foi por este processo que uniu a física (óptica) e a química (fixação da imagem) que conhecemos a fotografia e o registro de imagens do mundo que nos cerca, incluindo-se aí as fotografias de Sebastião Salgado. Em seus 45 anos de profissão, Sebastião Salgado fotografou por cerca de 35 anos utilizando as câmeras fotográficas de filme, ou seja, ao iniciar o Projeto Gênesis, em 2004, o dispositivo utilizado era analógico, embora com filmes de formato e sensibilidade diferentes, o médio formato de Iso $^{3} 320$ (Salgado, 2014, p. 115).

No que diz respeito aos aspectos óticos como a entrada de luz e suas variáveis como tempo de exposição pelo obturador e abertura de diafragma, há algumas mudanças registradas na passagem da tecnologia analógica para a tecnologia digital na fotografia. Para este trabalho assinalamos como relevante a mudança na forma de registro e armazenamento das imagens fotografadas. A imagem deixa de ser exposta em um suporte físico, o filme sensível à luz, e passou a ser registrada por um sensor elétrico e armazenada em um cartão de memória. Silva (2016) pontua bem a lógica do registro fotográfico:

A fotografia, como técnica de produção de imagens, desde seu início mantém a mesma cadeia de ação que estabelece seus procedimentos de uso. Essa cadeia de eventos mantém-se como aquilo que pode ser entendido como

3Sigla, em inglês, de International Standards Organization (ISO). Unidade de medida empregada para designar a sensibilidade de uma película fotográfica (Rabaça e Barbosa, 2001) 
constituinte de qualquer sistema fotográfico de qualquer época e qualquer parte do mundo. Grosso modo, tal caráter universal, na sua concepção mais simples, consiste numa caixa com entrada de luz que pode ser controlada. (Silva, 2016, p. 35)

Embora a história das câmeras fotográficas digitais remonte aos anos 1970, a popularização comercial desses dispositivos se deu mais intensamente a partir dos anos 1990 (Silva, 2016, p. 125), inicialmente nos Estados Unidos e Europa e, depois, nos demais países. Foi preciso que se passassem mais de 15 anos, considerando o início da comercialização, em 1991, para que Sebastião Salgado começasse a utilizar esse dispositivo. Os primeiros testes com equipamentos de fotografia digital foram feitos por Sebastião Salgado em meados de 2008, quando o Projeto Gênesis já estava em curso (foi iniciado em 2004) e houve garantias de que havia progressos consistentes na tecnologia e que sustentariam a migração do analógico para o digital, apesar de problemas existentes no que dizia respeito à conservação e à manutenção dos arquivos digitais.

Para além das questões tecnológicas, Sebastião Salgado justifica a opção, ainda que tardia, pelo digital por outros dois motivos: a dificuldade de se passar pelos serviços de segurança nos aeroportos em todo o mundo, especialmente após os atentados ao World Trade Center, nos Estados Unidos, em 11 de setembro de 2001; e também pela diminuição da poluição causada pelos produtos químicos utilizados em grande quantidade na revelação dos filmes. Sobre a facilidade em viajar sem correr o risco de danificar filmes pelos aparelhos de raio $\mathrm{X}$ nos aeroportos, o fotógrafo afirma em trecho do documentário Revelando Sebastião Salgado:

O digital para mim, mudou muita coisa e ao mesmo tempo mudou muito pouca coisa. Na realidade, muito mais fácil, para mimhoje, fotografar com o digital. Quando eu viajava com a câmera de filme, no início do Projeto Gênesis, eu levava na mão entre 28 e $30 \mathrm{~kg}$ porque eu tinha que levar 600 rolos de filme que era uma quantidade razoável de filme porque se eu fosse para um local e ficasse bastante tempo, eu tinha que ter filme. Então era uma briga em todas as viagens, primeiro com a segurança no aeroporto para não passar no RX. Olha, eu era a primeira pessoa a estar na fila para entrar no avião porque eles tinham que verificar meus filmes, e na verdade, eu era o último a entrar no avião. Até eu tirar as películas todas, verificar uma por uma na mão, era uma tensão permanente. Então, isso me facilitou muito a vida porque hoje, numa caixinha que pesa menos de um quilo, 
eu levo muito mais material que isso. Eu levo tudo na mão, como todo mundo. Eu passei a ser um cidadão normal outra vez. (Revelando Sebastião Salgado, 2012, 1h5'32")

Ainda no mesmo documentário, um pouco mais a frente, justificando sua militância ambiental, assumida publicamente com a criação do Instituto Terra, em Aimorés, Minas Gerais, Salgado fala da preocupação com a grande quantidade de poluentes lançados nas redes públicas de coleta de esgoto e afirma:

Todo o processo do laboratório era um processo muito sujo, muito, profunda poluição. A quantidade de ácido que você tinha que usar para revelar os filmes, depois você tinha que jogar fixador, revelador, são ácidos, todos no esgoto, isso caía na rede pública, isso acaba poluindo as águas e infiltrando no solo. É muito sujo, isso para mim terminou. (Revelando Sebastião Salgado, 2012, 1h6'50").

Para além das questões apresentadas publicamente por Sebastião Salgado, é importante ressaltar que, a despeito da mudança da tecnologia, o dispositivo "câmera fotográfica", com o qual o fotógrafo está habituado a trabalhar ao longo de mais de quarenta anos de profissão, não sofreu mudanças significativas em seu desenho externo ou design. Consideramos aqui como externo o que, visualmente, pode ser percebido pelos indivíduos que não estão familiarizados com os aparatos e dispositivos fotográficos. Sendo assim e ainda considerando o dispositivo como um aparato técnico operado por um sujeito e toda a sua experiência de vida, não haveria, pelo menos hipoteticamente, alterações físicas externas nas câmeras fotográficas digitais que as deixassem substancialmente diferentes das câmeras analógicas e que pudessem justificar ou não a opção por aderir à tecnologia digital.

Pensar câmeras fotográficas e todo o aparato utilizado e carregado por um fotógrafo profissional nos remete, em alguma medida, para o lado romantizado da profissão. Muitas pessoas, ao verem alguém com equipamentos fotográficos profissionais, ou semi-profissionais, coletes, tripés, entre outros, ativa um imaginário de que o cidadão fotógrafo é aquele que tudo vê e apresenta as imagens capturadas para as demais pessoas ou ainda aquele que registra, com suas lentes, tudo o que acontece distante. Então, ao pensar a mudança tecnológica apresentada por Sebastião Salgado no que diz respeito ao transporte 
de cartões de memória no lugar dos rolos de filmes, significa pensar também que, para além das questões sobre a preservação da qualidade dos filmes antes de seu uso e todos os procedimentos de segurança a que era submetido nos aeroportos, por exemplo, haveria uma mudança no imaginário coletivo existente sobre a fotografia e seus processos de revelação e ampliação desses filmes e que estaria acoplado ao fotógrafo. Em certa medida, facilitar a vistoria dos suportes fotográficos (cartões de memória) provocaria um certo apagamento do perfil existente do fotógrafo para dar lugar a um novo fotógrafo mais tecnológico e ao mesmo tempo mais discreto, diferente do personagem existente no imaginário popular, como aquele observador do mundo, que carrega uma grande quantidade de equipamentos e mostra para as pessoas aquilo que, presencialmente, elas não conseguem visualizar com seus próprios olhos.

Há, nesse ponto, outro aspecto a ser considerado sobre a fotografia praticada e adotada por Sebastião Salgado. Em diversos momentos, como entrevistas concedidas ao longo de diversos anos, o fotógrafo afirma que foi preparado, pela vida e ao longo da vida, para fazer o que ele mesmo chama de fotografia social.

Quando me perguntam como cheguei à fotografia social, respondo: foi como um prolongamento de meu engajamento político e de minhas origens. Vivíamos cercados por exilados que, como nós, haviam fugido de ditaduras da América do Sul, e também da Polônia, de Portugal, de Angola... Assim, foi natural começar a fotografar os emigrados, os clandestinos. (Salgado, 2014, p. 41)

No universo identificado como o da fotografia social, Salgado fotografou, prioritariamente, o ser humano, num tipo de fotografia de Henri CartierBresson chamou de "militante" (Cartier-Bresson, 2015, p.106), ou seja, um trabalho engajado, com o qual o fotógrafo se identifica totalmente.

O trabalho fotográfico de Sebastião Salgado que mostra situações de degradação humana ou de sofrimento das pessoas, mostra seu posicionamento político, por meio do qual o fotógrafo se identifica, tanto fora, quanto dentro da prática profissional. Ao assumir o discurso ecológico de defesa da preservação do planeta, marcado temporalmente pela criação do Instituto Terra e pelas concepção e execução do Projeto Gênesis, Salgado também demarca um espaço 
de atuação política na área ambiental. Embora fotografando paisagens pela primeira vez, sua fotografia continua atuante para, por exemplo, fazer denúncias sociais sobre destruições ambientais e a necessidade de preservação do que ainda existe.

Mesmo com a diferença dos assuntos fotografados, mantém-se, em certa medida, o engajamento e a militância nos trabalhos. Se, ao fotografar pessoas, Salgado realiza um trabalho essencialmente político ao apresentar determinadas situações degradantes ao mundo, esse posicionamento crítico e político também é percebido ao retratar locais "preservados" do Planeta, por se tratar de denúncias de destruição ambiental, em diversos aspectos, e ressaltar a necessidade de preservação e de mudança de comportamento dos seres humanos em relação ao meio ambiente global.

Então, ao fazer essa reflexão sobre o trabalho social de Salgado, podemos inferir que o posicionamento político do fotógrafo inclui, também, as questões técnicas e tecnológicas inerentes à fotografia analógica ou à fotografia digital. Para além disso, o trabalho fotográfico de Sebastião Salgado seria, então, sua forma de expressão e de se relacionar com o mundo em que vive.

\section{Pranchas de contato ou folhas de contato}

Dando sequência ao percurso da reflexão, tomaremos aqui, duas definições intimamente relacionadas à tecnologia analógica da fotografia: negativo e prova de contato. Ambos os conceitos têm relação com o filme, película fotossensível utilizada nas câmeras fotográficas para o registro da imagem por meio da luz.

Neste primeiro momento, vamos retomar os conceitos trazidos por Barbosa e Rabaça (2001) que podem contribuir com as reflexões propostas neste trabalho que têm como objeto a fotografia e sua prática. Para os autores, negativo é:

Imagem fotográfica própria para obtenção de cópias positivas, formada após a revelação, sobre um filme, chapa ou papel. Seus tons e cores não correspondem aos do assunto original. No negativo branco-e-preto, as zonas claras ou transparentes representam os tons escuros do assunto original e as zonas escuras ou opacas representam os tons claros. Já os negativos coloridos são 
complementares em cor e matiz às cores originais do assunto (p. ex.: azul ao amarelo, verde ao magenta, vermelho ao ciano), e podem produzir, além de cópias coloridas, cópias em branco-e-preto e transparências em cor. A aparência alaranjada, comum nos negativos coloridos, deve-se a uma máscara de balanceamento própria para garantir uma fidelidade básica de cor. (Barbosa e Rabaça, 2001, p. 506 e 507)

E prova de contato é:

Cópia fotográfica obtida a partir de contato direto do negativo como papel sensível, por meio do ampliador ou de uma copiadora apropriada, sem ampliação da imagem (neste caso, a cópia apresenta o mesmo tamanho do negativo). Por este processo, várias chapas são reproduzidas numa única folha de papel, que serve de prova para seleção das fotos a serem ampliadas. (Barbosa e Rabaça, 2001, p.182)

Diante dessas definições, seguimos adiante com as reflexões sobre os negativos e as pranchas de contato. Desde o início da fotografia, o desafio era registrar, em um suporte físico, as imagens capturadas pela câmera obscura. Podemos citar, somente a título de exemplo, vidro, metal, colódio úmido, entre outros, até chegar no que conhecemos como filme fotográfico e seus processos de revelação e fixação da imagem no papel. Foi um longo processo de evolução de técnicas e materiais, e também de redução de custos, que culminou com a popularização da fotografia, especialmente na segunda metade do século XX.

Portanto, as definições e conceitos de negativo e prova de contato foram, e ainda são, aplicadas a um dispositivo, físico, a partir do qual as imagens fotográficas eram registradas e armazenadas para sua reprodução, teoricamente, infinita. Esses dispositivos ocupavam, então, os primeiros degraus, por assim dizer, de um processo de edição fotográfica, em que o fotógrafo, após o registro de suas imagens, fazia o trabalho de seleção de imagens de acordo com a finalidade de cada trabalho.

E com Sebastião Salgado, esse processo, embora particular, não era diferente. Com cada etapa dos trabalhos de campo finalizada, procedia-se à revelação dos filmes, criando-se os negativos e, num segundo momento, faziam-se as chamadas pranchas de contato. E o processo de edição seguia a partir desses 
dois dispositivos cujas existências são interdependentes: o negativo e a prancha de contato.

Com a gradual substituição da tecnologia analógica pela tecnologia digital na fotografia, surgiram, como em processo de mudança, questionamentos e questões em relação à novidade tecnológica. Embora houvessem as vantagens quando se falava, por exemplo, sobre facilidade e velocidade na transmissão de arquivos, havia pontos questionáveis como a saturação de cores, uma vez que o mecanismo de registro e armazenamento de arquivos era elétrico. Além disso, já se sabia que as mídias digitais de armazenamento podem ter problemas e provocar perdas de trabalhos. Em nossa leitura, talvez seja esse último ponto que tenha adiado a decisão de Sebastião Salgado em aderir à tecnologia digital.

O problema era a conservação dos arquivos em discos rígidos. Ao longo de quase dois anos, lutamos como loucos, com Philippe e os impressores da agência, Valérie Hue e Olivier Jamin, e depois o laboratório Dupon. Finalmente conseguimos obter negativos preto e branco de $4 \times 5$ (polegadas) a partir dos arquivos digitais. Esses negativos são de excelente qualidade. Assim, continuamos a fazer cópias analógicas a partir de uma imagem digital. Conseguimos evitar, portanto, os problemas de conservação, que, até o momento, continua sendo uma questão crucial. (Salgado, 2014, p. 117 e 118)

Essa preocupação nos parece legítima, uma vez que sabemos que arquivos de negativos ou de imagens ampliadas em papel fotográfico podem ter grande durabilidade se conservadas em condições adequadas. Entretanto, parece não haver, ainda, a mesma garantia para os arquivos digitais.

A partir dessa ponderação que Salgado nos apresenta, compreendemos as preocupações com a conservação do material produzido ao mesmo tempo que novas questões se apresentam para nossa reflexão. A primeira delas diz respeito à origem do negativo como dispositivo. Se o negativo é o filme revelado por meio de processos químicos realizados ou provocados na ausência da luz, no interior dos laboratórios, poderíamos chamar de negativo o novo dispositivo gerado a partir de um arquivo digital? E consequentemente poderíamos chamar de prancha de contato o dispositivo gerado a partir desses negativos, assim 
chamados por Sebastião Salgado? Se pensarmos a história e a evolução do suporte filme ou película fotográfica, o que temos nesse momento seria outro dispositivo, apenas por sua origem e não pela finalidade.

Se considerarmos a finalidade desses novos dispositivos, por exemplo, no processo de edição fotográfica realizado pelo fotógrafo, poderíamos tomar esses nomes emprestados, ainda que temporariamente, para compreender uma metodologia de trabalho que, aparentemente, pretende-se, da parte e intenção do fotógrafo, manter inalterada independente da migração tecnológica.

Poderíamos pensar, também, em um primeiro momento, que esse seria um movimento de apropriação tecnológica feito por Sebastião Salgado, ao utilizar conceitos atrelados inicialmente à fotografia analógica em sua prática fotográfica e editorial realizada a partir da tecnologia digital. O próprio fotógrafo ressalta, por exemplo, a melhor qualidade das impressões a partir do que ele chama de "negativo digital". Sendo assim, são solucionadas algumas questões importantes como o armazenamento e preservação do material fotográfico e o alcance de uma alta qualidade gráfica para os livros e exposições realizadas. Por outro lado, poderia se pensar em quanto tempo mais Sebastião Salgado fotografaria se não fizesse essa migração tecnológica do analógico para o digital. Por quanto tempo ainda existiriam filmes para Sebastião Salgado fotografar? E existiriam os produtos químicos utilizados nos processos de revelação e ampliação das fotos? Buscar respostas para essas e outras perguntas nos leva ao movimento que a própria indústria fotográfica fez, e faz, no que diz respeito aos produtos que são oferecidos aos clientes em escala mundial, sejam eles fotógrafos profissionais ou amadores.

\section{Os processos de edição}

Ainda refletindo sobre os dispositivos como objetos operados por sujeitos e não somente como um aparato técnico isolado e considerando que Sebastião Salgado fez um processo de transição entre as duas tecnologias fotográficas disponíveis naquele momento (2008), outro aspecto a ser considerado é o processo de edição que o fotógrafo apresenta nas duas peças narrativas em 
análise nesse estudo: o documentário Revelando Sebastião Salgado, de Betse de Paula e Juliano Ribeiro Salgado, e o livro autobiográfico De minha terra à Terra.

A despeito da mudança de tecnologia para a produção de suas fotografias e realização de seus projetos, Sebastião Salgado afirma que, para ele, mudou muito e não mudou nada em sua fotografia. Quando ele diz que mudou muito, refere-se especialmente ao transporte de filmes fotográficos pelos aeroportos do mundo. Por ser um dispositivo sensível, os filmes sofriam alterações em cores e saturações ao passar pelos aparelhos de raio X. Diante disso, era feita a verificação manual da bagagem de mais de 600 rolos de filmes levados a cada viagem. E com os cartões de memória, ainda que dispositivos eletromagnéticos, não há problemas com os dispositivos de verificação e segurança. Além disso, o peso desses cartões é significativamente menor que o dos filmes. Ao explicar o que mudou pouco, Salgado afirma:

Eu não sei editar, isto é, fazer minha seleção de imagens numa tela de computador. Não consigo. Nunca trabalhei numa tela. A passagem para o digital não modificou minha maneira de trabalhar. A única diferença é que, em vez de carregar uma maleta de 28 quilos, transporto agora setecentos gramas em cartões de memória que não temem os raios X. Quando viajo, não levo nem computador nem disco rígido. Fotografo olhando apenas no visor, como fiz a vida inteira. Ao voltar para a Amazonas Images, imprimimos as folhas de contato na impressora jato de tinta e eu as analiso com uma lupa, como sempre fiz. A seguir, Adrien Bouillon faz cópias de leitura em 13 x 18 $\mathrm{cm}$. Faço uma primeira seleção com Françoise Piffard e, sob a coordenação de Marcia Mariano, responsável pelo contato com os laboratórios, Valérie e Olivier fazem cópias em formato $24 \times 30 \mathrm{~cm}$. Não fiz nada além de mudar de suporte ao passar do filme para o digital. Minha linguagem continua a mesma. A grande diferença é a qualidade da impressão, mil vezes melhor. (Salgado, 2014, p. 118)

A partir dessa fala surge nova questão: se as tecnologias são diferentes no que diz respeito à captação e armazenamento das imagens, as técnicas e procedimentos de edição fotográfica deveriam ser distintas ou podem ser as mesmas, apesar de algumas adaptações? Em princípio, a resposta poderia levar em consideração as particularidades de cada discurso, mas no caso de Sebastião Salgado, talvez isso não se aplique, uma vez que suas práticas de edição estejam 
voltadas para projetos de longa duração e não tenha a necessidade de transmissão rápida de arquivos fotográficos, como é o caso de jornais diários ou revistas. Ao que tudo indica, a substituição da tecnologia analógica pela digital atenderia às mudanças impostas pelo mercado de produtos fotográficos, sob pena de, em algum momento, não existirem suprimentos necessários para a execução dos projetos realizados por Sebastião Salgado, com a publicação de fotolivros e realização de exposições. Pensar também nessa questão mercadológica nos faz refletir que a migração tecnológica do analógico para o digital, com todos seus ônus e bônus no que diz respeito à dificuldade de armazenamento dos arquivos gerados ou o ganho considerável de qualidade gráfica alcançado, foi, em certa medida, a forma que Sebastião Salgado encontrou para se manter presente e atuante no mercado fotográfico, a despeito da tecnologia utilizada. Ao encontrar alternativas viáveis para continuar seu trabalho de edição sem a necessidade de fazê-lo no computador, Salgado aponta que continua construindo narrativas visuais que transmitem, sim, discursos fotográficos com claro posicionamento político, independente do objeto escolhido para seus projetos, sejam pessoas ou natureza, com adaptações, não no modo de olhar, mas nos processos quepassou a utilizar para construir esses discursos. Ficam, ainda, os questionamentos sobre nomenclaturas de dispositivos, e seguem as reflexões sobre a tecnologia e a técnica fotográficas. 


\section{Referências}

BARBOSA, Gustavo e RABAÇA, Carlos Alberto. Dicionário de Comunicação. 2 ed. revista e atualizada. Rio de Janeiro: Campus, 2001.

CARTIER-BRESSON, Henri. Ver é um todo - Entrevistas e conversas 19511998. Tradução: Julia da Rosa Simões. São Paulo: Gustavo Gili, 2015.

DELEUZE, Gilles. ¿Que és un dispositivo? In: DELEUZE, Gilles. Michael Foucault, filósofo. Barcelona: Gedisa, 1990.155-161 p.

REVELANDO Sebastião Salgado. Direção: Betse de Paula. Rio de Janeiro: Aurora Cinematográfica. 1 filme (75 min). Cor. 2012.

SALGADO, Sebastião. FRANCQ, Isabelle. Da minha terra à terra. Tradução: Júlia da Rosa Simões. 1 ed. São Paulo: Paralela, 2014.

SALGADO, Sebastião. Gênesis. Taschen, 2013

SILVA, Wagner Souza e. Foto o|Foto 1. São Paulo: Fapesp, Editora da Universidade de São Paulo, 2016.

VILLEGAS, Alex. Como funciona a captura digital. In: VILLEGAS, Alex. O Controle da Cor - Gerenciamento de Cores Para Fotógrafos. Santa Catarina: Editora Photos, 2009. P. 30-46.

https://www.papodecinema.com.br/filmes/revelando-sebastiao-salgado, acesso em 2 de agosto de 2018, às 22h59 